\title{
A Novel Approach for Grid Integration of Cascaded H-bridge Multilevel Inverter Under Partial Shading Condition
}

\author{
Swetapadma Panigrahi, Amarnath Thakur \\ Departement of Electrical and Electronics Engineering, NIT Jamshedpur, India
}

\begin{tabular}{ll}
\hline \hline Article Info & ABSTRACT \\
\cline { 2 - 3 } Article history: & $\begin{array}{l}\text { A modular cascaded H-bridge PV inverter based system is presented in this } \\
\text { paper. It helps in obtaining the maximum output power of PV system along } \\
\text { with increase the overall efficiency of the whole system. Moreover to utilize } \\
\text { the system up to the best a distributed MPPT controller is attached with each } \\
\text { Revised Jul 3, 2018 }\end{array}$ \\
$\begin{array}{l}\text { Accepted Jul 5, 2018 } \\
\text { that leads to imbalance grid current, a control technique called the } \\
\text { Keyword: }\end{array}$ & $\begin{array}{l}\text { modulation compensation is adopted in such a way that if three phase } \\
\text { unbalanced voltage varies directly according to unbalanced power, the } \\
\text { injected zero sequence voltage components make the grid current balanced. }\end{array}$ \\
Cascaded H-bridge &
\end{tabular}

Copyright (c) 2018 Institute of Advanced Engineering and Science. All rights reserved.

Corresponding Author:

Swetapadma Panigrahi,

Departement of Electrical and Electronics Engineering,

National Institute of Technology,

Jamshedpur, Jharkhand, India, 831014

Email: dipa.tat@gmail.com

\section{INTRODUCTION}

From the last couple of years renewable energy sources are growing extensively to fulfill the energy demand of consumers. Among the different energy sources, solar energy is the most reliable and sustainable one [1]-[3].With the wide development of power electronics technology it becomes easier to integrate various PV inverters with the utility grid. A PV-inverter is the main component for integration in a grid-connected application. It converts the DC power available from solar panel into AC power that is fed into an utility grid. PV panels are connected either in series or parallel or both to obtain the required voltage and power. This arrangement is called as centralized PV inverter. But the requirement of high voltage DC cable between PV panel and inverter limits its usage.

Till now different types of PV inverters are developed based on PV module connected method, utilization of transformer and number of power stages [4]. Among the various inverter toplogies the multilevel inverter configuration is paying the attention of the researchers worldwide for large scale applications. Because of its multilevel structure the output waveform obtained in the grid side must be sinusoidal with less harmonics content [5]. It does not require any bulky low frequency transformer for its integration with the grid. Moreover,because of the requirement of individual DC source for each H-bridge configuration, the voltage control can be done individually. A single phase seven level CHB comprises of three H-bridges each fed by multiple strings of PV panels through their own individual H-bridge is presented in Figure 1. In such arrangement, the individual MPPT, called distributed MPPT technique is applied to track the extreme power of each PV panel [6]. 


\section{SYSTEM DESCRIPTION}

\subsection{Modular cascaded H-bridge multilevel inverter}

A seven level CHB inverter produces the output voltage values (levels) with respect to negative terminal of the capacitors. If $\mathrm{n}$ represents the number of step of phase voltage with respect to the negative terminal of the inverter, then the number of stages $\mathrm{k}$ between two phases across load is represented as,

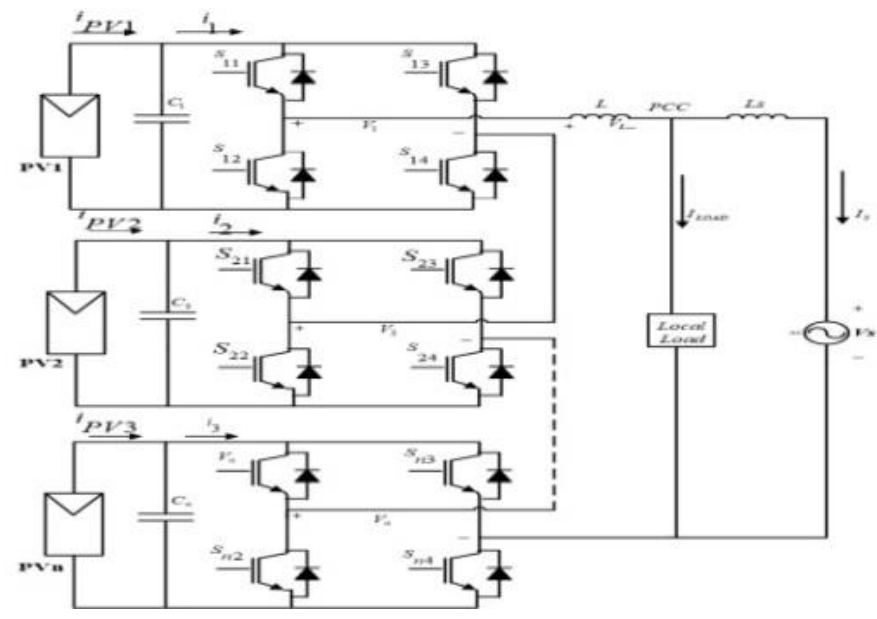

Figure 1. Configuration of single phase grid-connected PV system [7]

$$
k=2 n+1
$$

If the DC-link voltages are equal, at the load side 7-level voltage can be obtained. The output voltage can be represented by the upcoming equations:

$$
\left.\begin{array}{l}
V_{H 1}=\left(S_{11}-S_{13}\right) \cdot v_{C 1}=\mathrm{P}_{1} \cdot v_{C 1} \\
V_{H 2}=\left(S_{21}-S_{23}\right) \cdot v_{C 2}=\mathrm{P}_{2} \cdot v_{C 2}
\end{array}\right\}
$$

where $S_{X X}$ represents the switching state or it can be ON, 0 or OFF. $\mathrm{P}_{1}$ and $\mathrm{P}_{2}$ represent the discrete values having the values of $-1,0,+1$. For linearization, continuous switching functions $S_{1}$ and $S_{2}[-1,1]$ are taken in place of the functions $P_{1}$ and $P_{2}$ [8][9]. Equations (3) represent the dynamic behavior of the system that is represented as:

$$
\left.\begin{array}{l}
\frac{d i_{S}}{d t}=\frac{1}{L}\left(S_{1} v_{C 1}+S_{2} v_{C 2}-R i_{S}-v_{S}\right) \\
\frac{d v_{C 1}}{d t}=\frac{1}{C 1}\left(i_{P V 1}-S_{1} i_{S}\right) \\
\frac{d v_{C 2}}{d t}=\frac{1}{C 1}\left(i_{P V 2}-S_{2} i_{S}\right)
\end{array}\right]
$$

Due to the presence of isolated DC source in case of CHB, independent MPPT control can be possible and utmost power can be obtained from the entire system more efficiently. Nevertheless, since the possibility of independent voltage control through each $\mathrm{H}$-bridge, there is a power imbalance. This problem can be classified into two classes : 1) interphase (clustered) power imbalance, when power generated by each phase is not equal; and 2) inter bridge (individual) power imbalance, which happens when bridges connected to the same phase leg generates an unequal power. If this system cannot be considered seriously, dc-link voltage will float leading to voltage distortion at the grid side. Because of the inadequate irradiance obtained from sun, varying temperature and usage of the PV panels from long time, there is an unbalanced power supply to the CHB , causing unbalanced current at the grid side. Therefore this issue is considered seriously with the designing of suitable controller so that at the grid side balanced current is achieved [10][11]. 


\section{CONTROL STRATEGY}

PV mismatches is very hazardous problem in case of large PV system. Henceforth, for utmost power extraction from the system a control scheme is essentially needed. Generally two control scheme is proposed in this paper (i) MPPT control (ii) Inverter control.

\subsection{MPPT control}

To show the requirement of MPPT , 185W PV panel is considered that is connected to each Hbridge of level multilevel inverter of a three phase system. The P-V and I-V curves for $185 \mathrm{~W}$ panel is simulated in MATLAB/SIMULINK environment and are shown in Figure 2.The various plots at different radiations are shown. Each CHB inverter is connected to $185 \mathrm{~W}$ solar panel and for a single phase system $\mathrm{n}$ CHB inverters are connected in series. Likewise the whole three phase system is integrated with grid through inductor $\mathrm{L}$ that is used to minimize the switching current harmonics at the grid side. In order to resolve the PV mismatch issue distributed MPPT control technique is adopted.
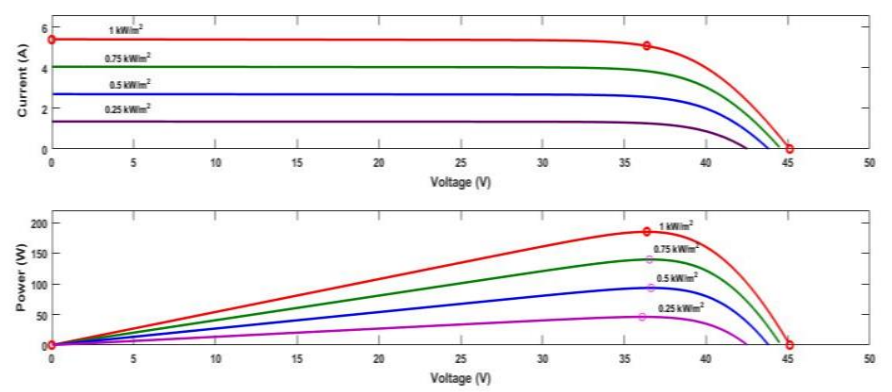

Figure 2. I-V and P-V characteristics of $185 \mathrm{~W}$ PV panel at different solar radiations

\subsubsection{Distributed MPPT control}

Various MPPT techniques were developed in order to extreme power from a PV panel [12]. In this paper, Incremental conductance MPPT method is adopted to generate the dc-link voltage reference for individual PV panel. Here the MPP point goes on adjusting its position irrespective of the environment changes. In order to track MPP, Incremental Conductance (IC) method compares the ratio of incremental conductance to instantaneous conductance value of PV module. Based on this value, the slope of P-V characteristic is varied and according to the change in slope, duty cycle of converter can be generated [13-16].

For MPP tracking, applying IC algorithm the following steps are taken into consideration:

a. When $\frac{d P}{d V}=0$, the error is zero and $V_{m p}$ can be found out .

b. When $\frac{d P}{d V}>0$ i.e $\frac{d P}{d V}>-\frac{I}{V}$, the MPP drags towards the left side of the curve (having a positive error).

c. When $\frac{d P}{d V}<0$ i.e $\frac{d P}{d V}<-\frac{I}{V}$, the MPP drags towards the right side of the curve (having a negative error).

After the MPPT tracking the dc link voltage reference is found to be $36.4 \mathrm{~V}$ as shown in Figure 3.

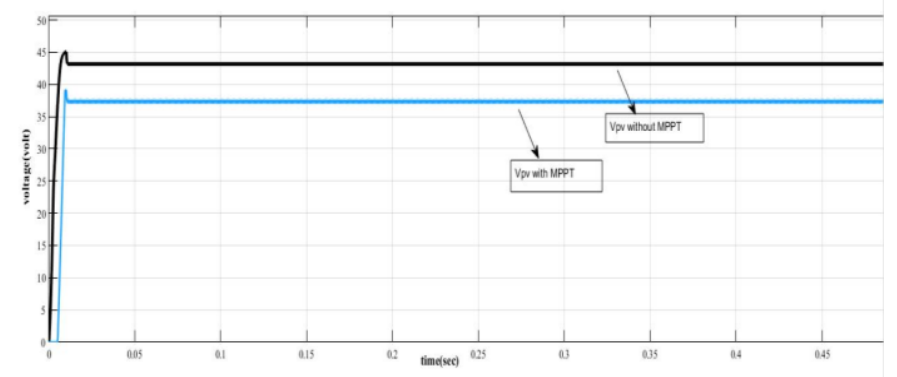

Figure 3. MPPT voltage of $185 \mathrm{~W}$ PV panel through incremental conductance method 


\subsection{Inverter control}

It comprises of control of both active and reactive power. It has two different control loops : one is called the voltage control loop that is used to set the capacitor voltage across each dc link and other one is called the current control loop that is required for the generation of the sinusoidalgrid current. Figure 4. shows the control scheme for the entire system. The sum of dc link voltage $V_{d c 1}$ to $V_{d c n}$ are compared with respective voltage reference to produce the sum of error that is passed through the total voltage controller loop to generate the reference current $i_{d r e f}$. As reactive power compensation is not taken into account in this paper, hence $i_{\text {qref }}$ is adjusted to be zero. The phase angle of grid voltage $\theta$ is determined by a three phase locked loop (PLL). The grid currents $i_{a}, i_{b}$ and $i_{c}$ are passed through $a b c$ to $d q$ converter circuit to generate the $i_{d}, i_{q}$ current coordinates. These current coordinates are again feed to a PI controller to generate the modulation index in $d q$ coordinates and with the help of $d q$ to $a b c$ controller modulation indices in $a b c$ coordinates are generated.

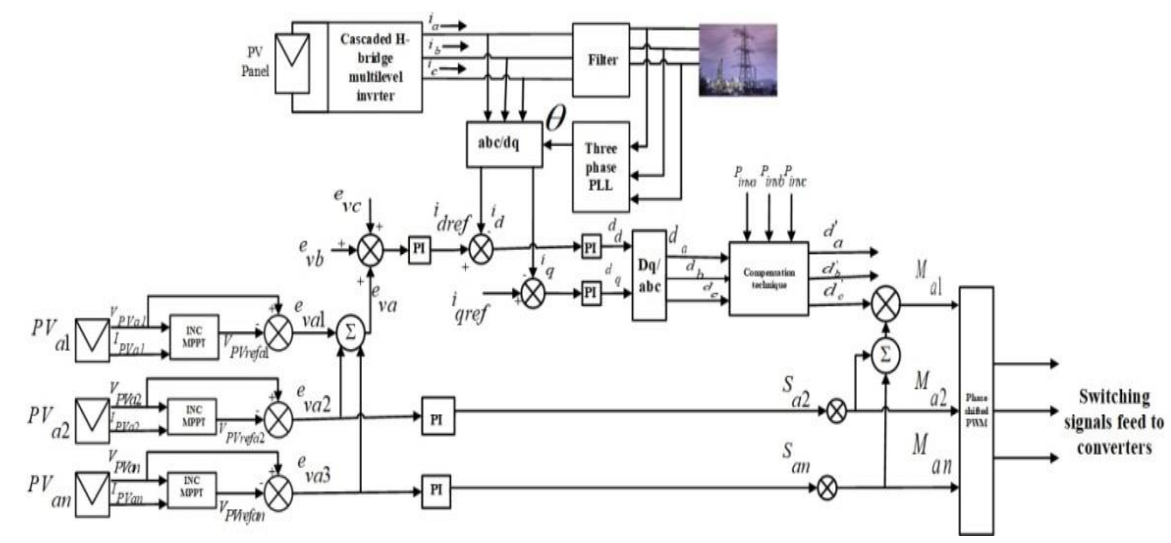

Figure 4. Control scheme for modular cascaded H-bridge multilevel PV inverter for three-phase system

For simplicity, take phase $a$ into consideration. Due to individual MPPT control, the generated voltages $v_{d c a 2}$ to $v_{d c a n}$ are controlled through $n$ - 1 loop. Each voltage controller gives the modulation index proportion of one H-bridge module in phase $a$. After multiplied by the modulation index of phase $a, n-1$ modulation indices can be generated. The calculation for phase $b$ and $c$ are also approachable in the same way to determine the modulation indices. A phase shifted modulation scheme is used for switching each $\mathrm{H}$ bridge inverter.

\subsubsection{Phase shifted modulation scheme}

There are different modulations techniques proposed for switching of multilevel inverters [17]-[21]. Among which PS-PWM is most popularly used to produce PWM control signals for switching of the inverters [22][23] . As partial shading phenomenon causes a serious issue in case of switching of cascaded inverter, hence the modulation index of each cell must be properly updated to consider unbalanced conditions at de side by producing different modulating signals. In order to achieve a balanced condition at grid side, cell with high power is assigned with high modulation index and with low power is assigned with low modulation index and hence each cell is modulated individually using the PWM, in order to provide an even power sharing among the cells. In PS-PWM all the triangular carriers are have the same frequency and peak-peak amplitude and a phase shift is made among any two immediate carrier waves. For $m$ Voltage levels, there is need of $(m-1)$ carrier signals and they are phase shifted with an angle of $\theta=\left(360^{\circ} / \mathrm{m}-1\right)$.

\subsection{Power balance control}

Partial shading is a common problem generally occurs in a large PV system that results in unequal power generation by the PV modules connected to each H-bridges, leading to unbalanced grid current as shown in Figure 5(a). However, the addition of zero sequence voltage $v_{N n}$ in each phase, manages in distribution of balanced power among the three phases so that at the grid side current is balanced as shown in Figure 5(b) [24]. If $v_{c i}^{*}$ is the output voltage of the inverter during partial shading condition then with the injection of $v_{N n}$, the output voltage of the inverter modified as, $v_{c i}^{*}+v_{N n}=v_{c i}$ (where $i=a, b, c$ for three phase voltages). It is based on the concept that if three phase unbalanced voltages at the grid side varies directly according to unbalanced power, the injected zero sequence voltage makes the grid current balanced [25]. Figure 6. shows 
the modulation compensation scheme used in control block to balance the grid current. In this technique, the weighted min-max method is adopted. The weighted ratio of unbalanced power in each phase is calculated by the formula,

$$
t_{i}=\frac{P_{\text {inavg }}}{P_{\text {invi }}}
$$

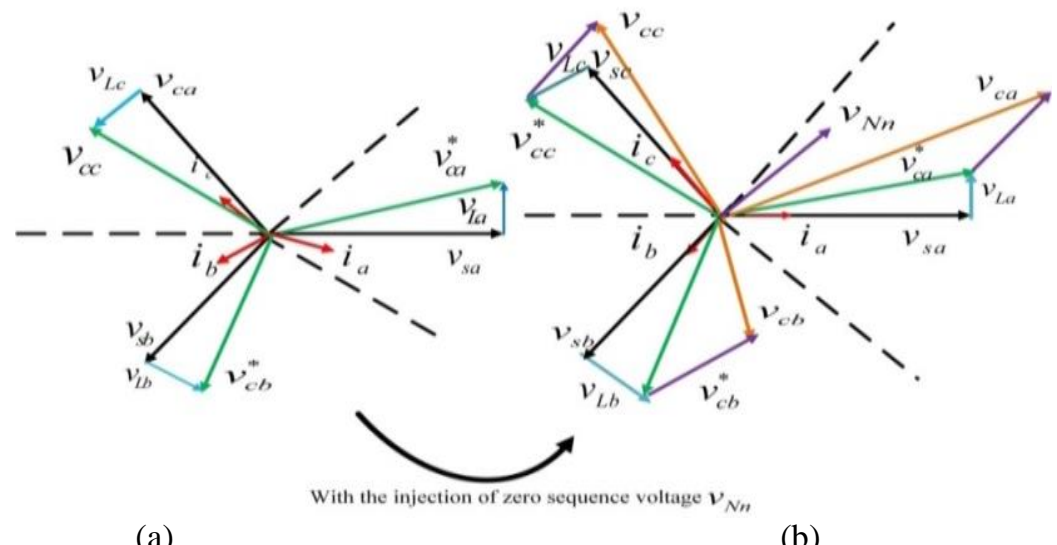

(a)

(b)

Figure 5. Vector diagrams of grid current balancing (a) without (b) with injecting zero sequence component

where $P_{\text {inavg }}$ is the average of the injected power in three phases and $P_{\text {invi }}$ is the inverter power in each phase.Then the zero sequence modulation index $d_{0}$ can be calculated by the formula,

$$
d_{0}=0.5\left\{\max \left(t_{a} \cdot d_{a}, t_{b} \cdot d_{b}, t_{c} \cdot d_{c}\right)+\min \left(t_{a} \cdot d_{a}, t_{b} \cdot d_{b}, t_{c} \cdot d_{c}\right)\right\}
$$

where $d_{a}, d_{b}, d_{c}$ are the modulation indices of phase $a, b$ and $c$ determined by the current loop controller. After determining the modulation indices the modulation index of each phase is modified as,$d_{j}^{\prime}=d_{j}-d_{0}$.

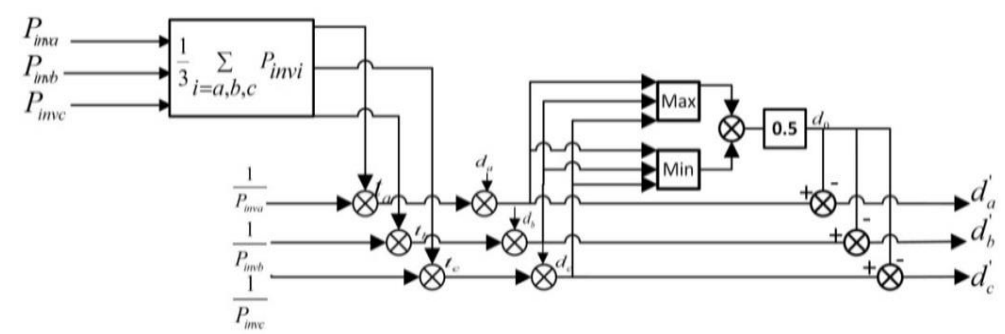

Figure 6. Scheme for modulation compensation through weighted min-max method.

\section{RESULTS AND ANALYSIS}

A seven level three phase cascaded multilevel inverter is initially simulated with $185 \mathrm{~W}$ of PV panel as dc source in MATLAB/SIMULINK environment. All PV panels are operated at $1000 \mathrm{~W} / \mathrm{m}^{2}$ and at $25^{0} \mathrm{C}$. At time $\mathrm{t}=0.8 \mathrm{sec}$ due to partial shading panel 1 and 2 of phase $a$ get the radiation of $600 \mathrm{~W} / \mathrm{m}^{2}$. From Figure 7(a). it shows that the MPP voltage obtained from panel 3 of phase $a$ is 36.4 while due to partial shading panel 1 and 2 give the MPP voltage of 36V.The MPP voltage obtained in phase $b$ is shown in Figure 7(b). It shows that partial shading effect the MPP voltage of phase $a$ only, whereas the other two phases are not affected by the environmental issues. Phase current obtained of phase a under distributed MPPT is shown in Figure 7(c). 

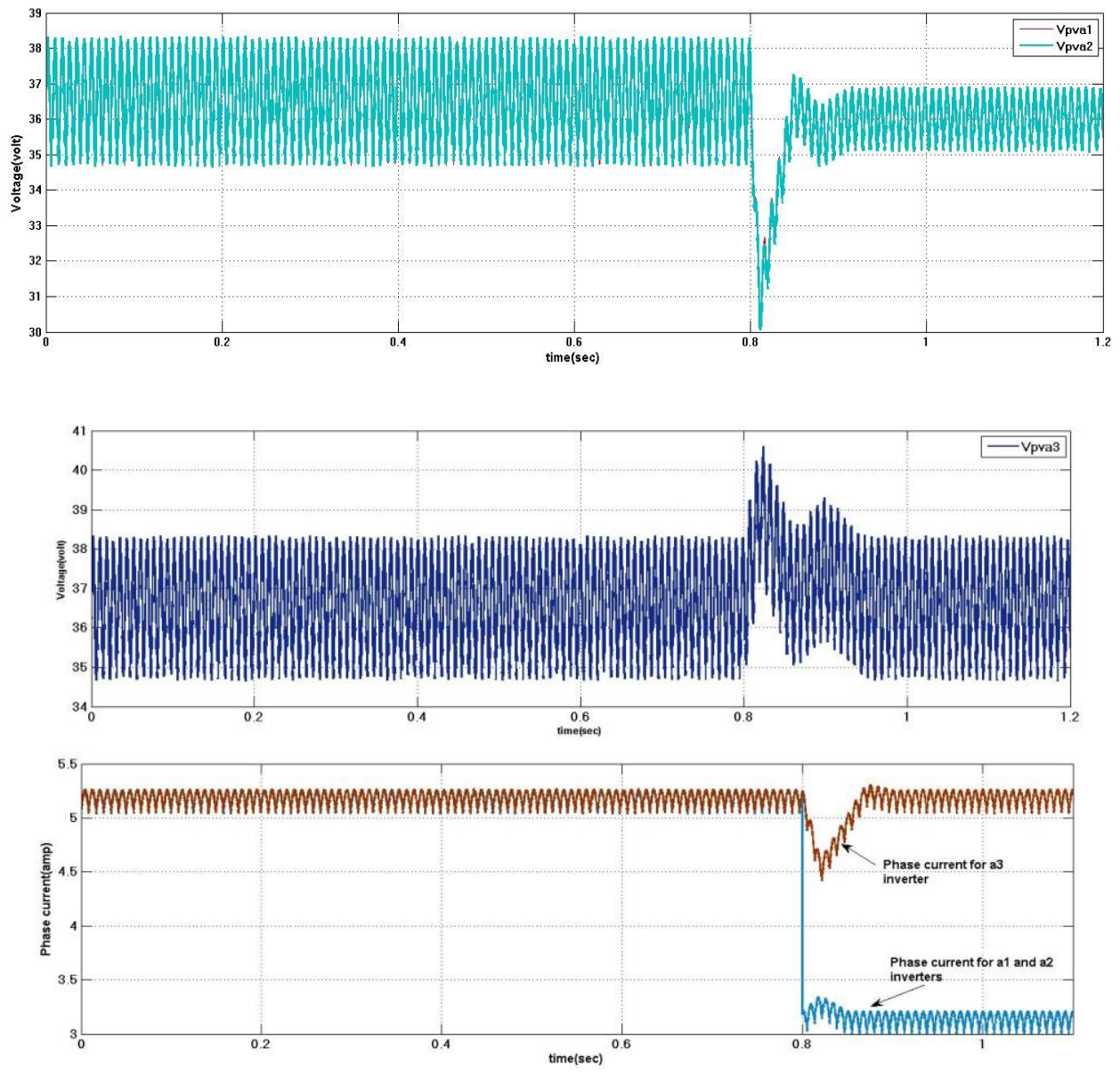

Figure 7 (a). DC link voltage obtained under distributed MPPT of panels 1 and 2 of phase $a$ under partial shading condition .Figure 7 (b). DC link voltage of phase $b$ obtained under distributed MPPT .Figure 7 (c). Phase current obtained of phase $a$ under distributed MPPT.

Power obtained from each phase is shown in Figure $7(\mathrm{~d})$. From time $t=0$ to $t=0.8$ sec, power extracted from three phase are approximately $535 \mathrm{~W}$ and at $\mathrm{t}=0.8 \mathrm{sec}$ because of change in radiation, power extracted from phase $a$ is $340 \mathrm{~W}$ causing a three phase unbalanced power. For this purpose, the modulation scheme with zero sequence voltage injection is adopted.

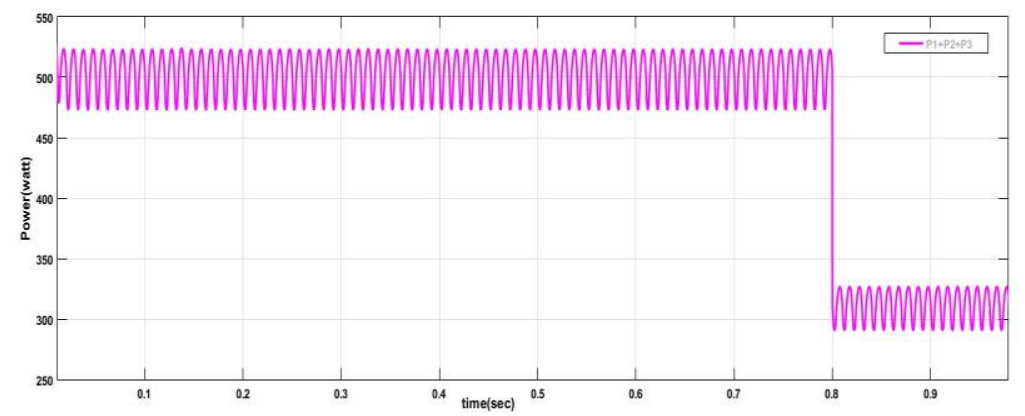

Figure 7 (d). Power extracted from three phases. 
After zero sequence voltage injection the inverter output voltage is shown in Figure 7 (e). It shows at $\mathrm{t}=0.8$ sec, due to zero voltage injection, voltage at the grid side becomes imbalance that causing a balanced grid current as shown in Figure 7 (f).

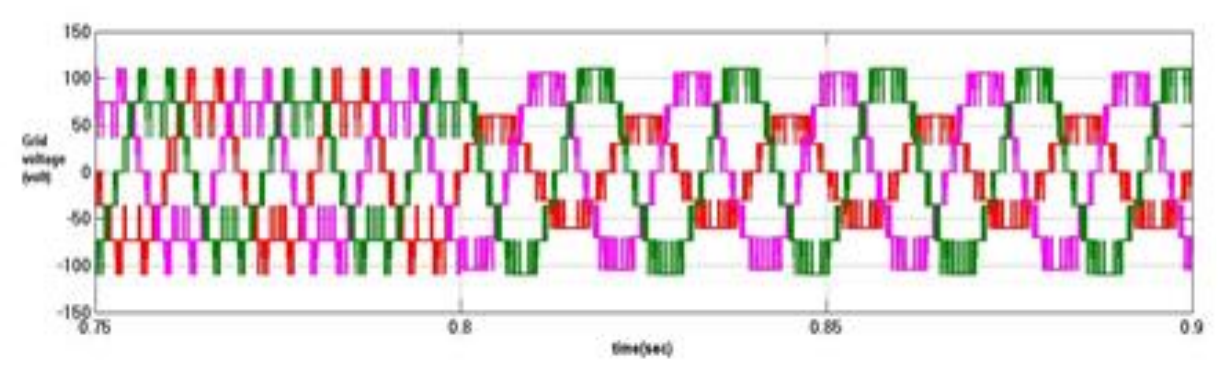

Figure 7(e). Three phase inverter output voltage after proposed modulation technique

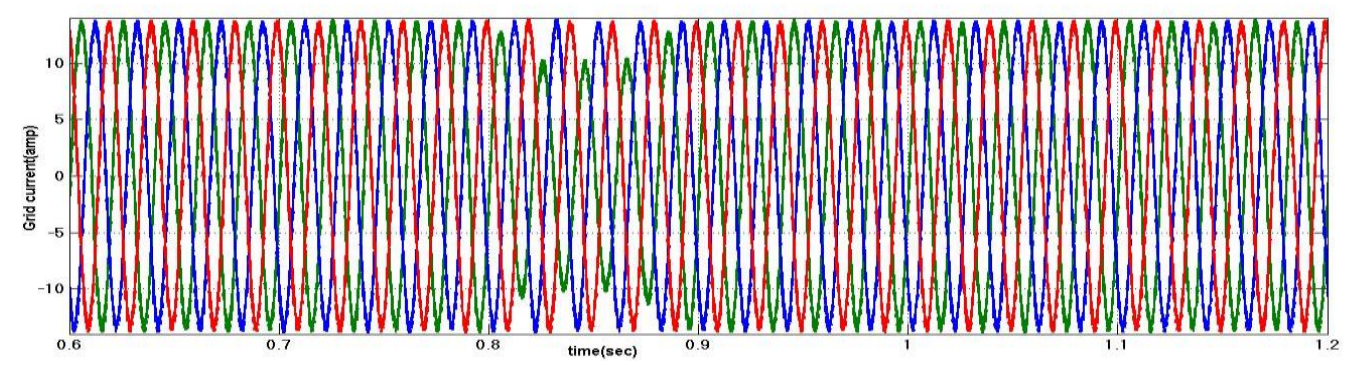

Figure 7(f). Balanced three phase grid current

\section{CONCLUSION}

A three phase cascaded H-bridge multilevel PV inverter with grid integration is proposed in this paper. In order to reduce the complexity and increase the efficiency distributed MPPT is applied to each PV panel. As partial shading is an important phenomenon to be considered in a large scale PV system that has direct impact on grid current balancing, a modulation compensation scheme is proposed. It helps in balancing the grid current by injecting a zero sequence voltage in proportion to power imbalnce so that maximum power is extracted.

\section{PARAMETERS TAKEN:}

Dc link capacitor $C=3600 \mu \mathrm{F}$, Inductor $L=2.5 \mathrm{mH}$, Load resistor $\mathrm{R}=0.1 \Omega$, Grid rated phase voltage $=60$ Vrms , Switching frequency $=1.5 \mathrm{Khz}$

\section{REFERENCES}

[1] Bose BK. Power Electronics, Smart Grid, and Renewable Energy Systems. Proceedings of the IEEE. Nov 2017; 105(11) : 2011-2018.

[2] Panigrahi S, Thakur A. Current trends in power electronics for wind and solar energy conversion systems. International Conference on Power and Embedded Drive Control (ICPEDC). Chennai, 2017 : 242-247.

[3] Devashish, Thakur A, Panigrahi S, Behera RR. A review on wind energy conversion system and enabling technology. International Conference on Electrical Power and Energy Systems (ICEPES), Bhopal, 2016 : $527-532$.

[4] Calais M, Myrzik J, Spooner T, Agelidis VG. Inverters for single-phase grid connected photovoltaic systems-an overview : 33rd Annual IEEE Power Electronics Specialists Conference. Proceedings (Cat. No.02CH37289), Cairns, Qld. 2002 : 1995-2000.

[5] Rodriguez J, Lai JS, Peng FZ. Multilevel inverters: A survey of topologies, controls, and applications . IEEE Trans. Ind. Electron. Aug. 2002; 49(4) : 724-738.

[6] Townsend D, Summers TJ, Betz RE. Control and modulation scheme for a cascaded H-bridge multi-level converter in large scale photovoltaic systems. Proc. IEEE ECCE . Sep 2012 : 3707-3714

[7] Xiao B, Hang L, Tolbert L M . Control of three-phase cascaded voltage source inverter for grid-connected photovoltaic systems. Twenty-Eighth Annual IEEE Applied Power Electronics Conference and Exposition (APEC), Long Beach, CA, 2013: 291-296. 
[8] Lai JS, Peng FZ. Multilevel converters-a new breed of power converters, IEEE Transactions on Industry Applications. May/Jun 1996; 32(3) : pp. 509-517.

[9] Villanueva, Correa P, Rodriguez J . Control of a single phase H-Bridge multilevel inverter for grid-connected PV applications. 13th International Power Electronics and Motion Control Conference, Poznan, 2008:451-455.

[10] Xiao B , Hang L, Mei J, Riley C, Tolbert LM, Ozpineci B . Modular Cascaded H-Bridge Multilevel PV Inverter With Distributed MPPT for Grid-Connected Applications. IEEE Transactions on Industry Applications. MarchApril $2015 ; 51(2)$ : 1722-1731.

[11] Syafaruddin. Problem-solving mismatching losses of photovoltaic (PV) system under partially shaded conditions. Makassar International Conference on Electrical Engineering and Informatics (MICEEI), Makassar, 2014: 1-4.

[12] Subudhi B, Pradhan R . A Comparative Study on Maximum Power Point Tracking Techniques for Photovoltaic Power Systems . IEEE Transactions on Sustainable Energy. Jan 2013; 4(1): 89-98.

[13] Sera D, Mathe L, Kerekes T, Spataru SV, Teodorescu R. On the Perturb- and-Observe and Incremental Conductance MPPT Methods for PV Systems. IEEE Journal of Photovoltaics. July 2013; 3(3) : 1070-1078.

[14] Soon TK , Mekhilef S . A Fast-Converging MPPT Technique for Photovoltaic System Under Fast-Varying Solar Irradiation and Load Resistance. IEEE Transactions on Industrial Informatics. Feb 2015; 11(1) : 176-186.

[15] Kish GJ, Lee JJ , Lehn PW. Modelling and control of photovoltaic panels utilizing the incremental conductance method for maximum power point tracking. IET Renewable Power Generation . July 2012; 6(4) : 259-266.

[16] Kjær SB . Evaluation of the "Hill Climbing" and the "Incremental Conductance" Maximum Power Point Trackers for Photovoltaic Power Systems. IEEE Transactions on Energy Conversion. Dec 2012; 27(4) : 922-929.

[17] Ahmed L, Borghate VB . Simplified space vector modulation technique for seven-level cascaded H-bridge inverter. IET Power Electronics. March 2014; 7(3) : 604-613.

[18] Rabinovici R, Baimel D, Tomasik J , A. Zuckerberger .Thirteen-level cascaded H-bridge inverter operated by generic phase shifted pulse-width modulation . IET Power Electronics . Sept. 2013; 6(8) : 1516-1529.

[19] Farah N, Lazi J. B. M, Talib M . Comparative Study of Three Different Topologies of Five-level Inverter with SPWM Modulation Technique . International Journal of Power Electronics and Drive System (IJPEDS). Dec 2017; 8(4): 1612-1621.

[20] Roy D, singh M, Roy T. A Novel Approach for Space Vector Based PWM Algorithm for Diode Clamped Three level VSI Fed Induction Motor Drive. International Journal of Power Electronics and Drive System (IJPEDS). Dec 2017; 8(4): 1534-1547.

[21] Udakhe P, Atkar D, Chiriki S, Borghate VB . Comparison of different types of SPWM techniques for three phase seven level cascaded H-Bridge inverter. IEEE 1st International Conference on Power Electronics, Intelligent Control and Energy Systems (ICPEICES), Delhi, 2016: 1-5.

[22] Sahoo SK, Bhattacharya T .Phase-Shifted Carrier-Based Synchronized Sinusoidal PWM Techniques for a Cascaded H-Bridge Multilevel Inverter. IEEE Transactions on Power Electronics. Jan 2018; 33(1): 513-524.

[23] Sun X, Wang B, Zhou Y, Wang W, Du H , Lu Z . A Single DC Source Cascaded Seven-Level Inverter Integrating Switched-Capacitor Techniques. IEEE Transactions on Industrial Electronics, Nov. 2016; 63(11) : 7184-7194.

[24] Wang F, Le Y, Mao W, Shineng Y, Zhang X . Power balance control scheme of cascaded H-bridge multilevel inverter for grid-connection photovoltaic systems. IEEE 8th International Power Electronics and Motion Control Conference (IPEMC-ECCE Asia), Hefei. 2016: 1539-1545.

[25] Yu Y, Konstantinou G, Hredzak B, Agelidis VG. Power Balance of Cascaded H-Bridge Multilevel Converters for Large-Scale Photovoltaic Integration . IEEE Transactions on Power Electronics; Jan 2016; 31(1): 292-303.

\section{BIOGRAPHIES OF AUTHORS}

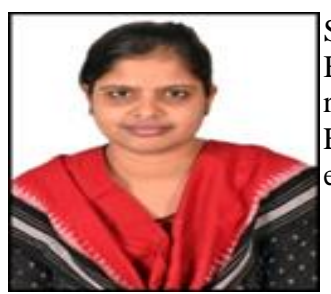

Swetapadma Panigrahi received B tech degree in Electrical and Electronics Engineering from BPUT Odisha, the M Tech degree from VSSUT,Burla, Odisha in the year 2010 and 2014 respectively. She is currently a research Scholar in the Department of Electrical and Electronics Engineering, National Institute of Technology Jamshedpur. Her area of interest include power electronics and renewable energy system.

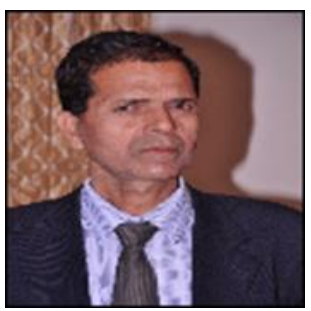

Amarnath Thakur received the B Sc (Engg.) degree in Electrical Engineering from MIT, Muzaffarpur, the $\mathrm{M}$ Tech degree from IIT(BHU), Varanasi and the $\mathrm{Ph} \mathrm{D}$ degree from Department of Elecrical Engineering, IIT Kharagpur in 1979, 1982 and 1997 respectively. He is currently a Professor in the Department of Electrical and Electronics Engineering, National Institute of Technology Jamshedpur. His area of interest include power electronics and renewable energy system. He is life member of the Indian Society for Technical Education New Delhi and Institution of Engineers, India. 